\title{
Transmission roles of symptomatic and asymptomatic COVID-19 cases: a modeling study
}

\section{Authors:}

Jianbin Tan $1 \dagger$, Yang Ge2†, Leonardo Martinez3, Jimin Sun4, Changwei Li5, Adrianna

Westbrook2, Enfu Chen4, Jinren Pan4, Yang Li6, Feng Ling4, Zhiping Chen4\$, Hui Huang1 Ye Shen $2 \ddagger$.

\section{Author affiliations:}

1 Sun Yat-Sen University, School of Mathematics, Guangzhou, China;

2 University of Georgia, College of Public Health, Department of Epidemiology and Biostatistics, Athens, Georgia, United States;

3 Boston University, Department of Epidemiology, Boston, United States;

4 Zhejiang Provincial Center for Disease Control and Prevention, Hangzhou, China;

5 Tulane University School of Public Health and Tropical Medicine, Department of

Epidemiology, New Orleans, Louisiana, United States;

6 Renmin University of China, School of Statistics, Beijing, China.

$\dagger$ Joint first authors; $\ddagger$ Joint corresponding Author. 
medRxiv preprint doi: https://doi.org/10.1101/2021.05.11.21257060; this version posted September 21, 2021. The copyright holder for this preprint (which was not certified by peer review) is the author/funder, who has granted medRxiv a license to display the preprint in perpetuity. It is made available under a CC-BY-NC-ND 4.0 International license.

\section{Key Points}

2 Question:

3 What is the transmissibility of COVID-19 asymptomatic and symptomatic cases, respectively?

4 To date, they have not been well quantified in existing literature.

5

6 Findings:

7 The transmissibility of asymptomatic and symptomatic COVID-19 increases with patient age.

8 The asymptomatic cases had a $66.72 \%$ lower transmissibility rate than symptomatic cases.

10 Meaning:

11 The transmissibility of asymptomatic COVID-19 cases is not low. Asymptomatic cases are

12 harder to detect compared to symptomatic cases. Consequently, the burden of asymptomatic

13 transmission could potentially dominate the spreading in certain scenarios. 


\section{Background}

16 COVID-19, caused by the novel coronavirus (SARS-CoV-2),[1] is a great threat to human

17 health.[2] Nonpharmaceutical interventions such as social distancing, case isolation and contact

18 quarantines are the most common tools for suppressing the pandemic in many countries where

19 vaccine supplements are limited.[3-5] However, much remains unclear regarding SARS-CoV-2

20 transmissibility which undermined the efforts for tailored interventions.[6,7] COVID-19 patients

21 may present and remain pre-symptomatic, asymptomatic, or symptomatic and transmission may

22 occur at each of these disease states.[8-10] Unlike the transmission caused by symptomatic

23 cases, pre-symptomatic and asymptomatic transmission are hard to detect and difficult to

24 measure as many surveillance systems rely on symptom-based population screening.[8,11-13]

25 Previous case studies suggested that asymptomatic COVID-19 individuals are less infectious

26 than symptomatic cases.[14,15] However, asymptomatic cases may spread for a longer period

27 due to reduced efficiency in case detection.[16] Several studies investigated the silent

28 transmission of SARS-CoV-2, but presented contradictory conclusions with estimated burden

29 ranged from $3 \%$ to $79 \%$.[16-18]

31 Without sufficient follow-up time, asymptomatic and pre-symptomatic cases are often

32 indistinguishable. Consequently, studies using population-level data to estimate of age-specific

33 transmission and susceptibility parameters commonly falls short of accuracy which potentially

34 explains for the heterogeneous findings from different studies.[19-21] Common issues were

35 modeling without data on observed asymptomatic infection[16-18,22] and inclusion of

36 pre-symptomatic cases as part of an asymptomatic classification,[19-21] . Meanwhile, few

37 studies assessing asymptomatic infectiousness and viral load with limited sample sizes fail to

38 capture the transmission dynamics.[14,15,23-30] No studies to date have attempted to combine

39 reliable case symptom classification with age-dependent transmissibility, social contact

40 measures, and susceptibility parameters at the population level to learn the transmission

41 dynamics. However, a comprehensive understanding of the age-specific symptomatic and

42 asymptomatic transmission dynamics at the population level is essential to the evaluation of an

43 epidemic and the creation of responding health policies. 
medRxiv preprint doi: https://doi.org/10.1101/2021.05.11.21257060; this version posted September 21, 2021. The copyright holder for this preprint (which was not certified by peer review) is the author/funder, who has granted medRxiv a license to display the preprint in perpetuity.

It is made available under a CC-BY-NC-ND 4.0 International license .

45 In this study, we report on a longitudinal cohort of all diagnosed COVID-19 infections, between

46 January 8th and February 23nd, 2020, from Zhejiang province, China. All patients without initial

47 symptoms were followed by at least 90 days to distinguish between asymptomatic and

48 pre-symptomatic cases, an essential procedure rarely implemented by previous studies to ensure

49 reliable classification of case symptoms. We then built age-stratified compartmental models to

50 study the age-dependent population-level transmission roles of symptomatic and asymptomatic

51 COVID-19 cases. 


\section{Methods}

Data sources

55 Zhejiang province is an eastern coastal province adjacent to Shanghai city with a population of 56 approximately 54 million individuals.[31] The first and only major wave of the COVID-19

57 epidemic in Zhejiang began on early January, 2020 and continued until late February, 2020 after

58 which only sporadic single-case events were observed. We included information from all

59 confirmed cases in this major wave (a total of 1342 cases), as well as a follow-up investigation

60 related to all detected asymptomatic infections to distinguish between asymptomatic and

61 pre-symptomatic cases. Individual-level data related to the symptom onset of symptomatic

62 infections, as well as COVID-19 confirmation dates and ages of both symptomatic and

63 asymptomatic cases were collected. On January 23rd ,2020, the provincial government changed

64 its infectious disease alert category to the highest level and, on February 1st, began a

65 comprehensive set of interventions.[32] As of April 10th, 2020, the date in which we restricted

66 our data for this analysis, no additional outbreak had been observed. Trained health professionals

67 investigated each confirmed case with a predefined questionnaire by which basic health and

68 demographic information were collected.

Definition of symptomatic and asymptomatic cases

71 All confirmed cases and their close contacts were isolated or quarantined after being identified

72 through contact tracing. During the isolation/quarantine period, cases and their contacts received

73 regular testing and daily symptom screening for fever, cough, and shortness of breath. Tests for

74 case confirmation were conducted using reverse transcription polymerase chain reaction

75 (RT-PCR) or viral genome sequencing on samples from throat swabs (oropharynx and

76 nasopharynx). If a case or contact had a positive test result but without any symptoms, they

77 would be temporarily classified as an asymptomatic/pre-symptomatic case at the time. All cases

78 were followed for at least 90 days after their initial positive test to distinguish between

79 asymptomatic and pre-symptomatic cases. Among these subjects, those who developed

80 symptoms later would receive a final classification as a symptomatic case. Others who had never

81 developed any symptoms between their initial positive test and first subsequent negative PCR

82 test would be classified as asymptomatic cases. 


\section{Model structure}

85 We divided the total population of Zhejiang province into seven age groups (Figure 1). To

86 consider transmission related to symptomatic and asymptomatic infections among different age

87 groups, our model contained 8 compartments for the $i^{\text {th }}$ age group: susceptible population $\left(S^{i}\right)$,

88 exposed contacts $\left(E^{i}\right)$, pre-symptomatic cases $\left(I_{p s}^{i}\right.$, infected but have not yet developed

89 symptoms), symptomatic cases $\left(I_{s}^{i}\right)$, asymptomatic cases $\left(I_{a}^{i}\right.$, infected but asymptomatic till

90 confirmed/recovery), and removed/recovery groups $\left(R_{c s}^{i}, R_{c a}^{i}, R_{h}^{i}\right)$. We assumed new infections

91 were driven by transmission from compartments of $I_{p s}^{i}, I_{s}^{i}$ and $I_{a}^{i}$ in all age groups.

93 Asymptomatic cases $\left(I_{a}^{i}\right)$ were infections without typical symptoms which were often

94 untraceable in the clinical survey and, therefore, their contribution to population-level

95 transmission would be underestimated. To account for this, we assumed only a proportion of

96 asymptomatic infections were detected $\left(R_{c a}^{i}\right)$, while others $\left(R_{h}^{i}\right)$ would be unconfirmed. We were

97 able to observe disease confirmation date but not the date of infection for the period from cases

98 becoming infectious to the diagnosis of COVID-19 $\left(\mathcal{A}_{1}^{i}\right)$ in those with confirmed asymptomatic

99 infection. Based on the virus shedding pattern of asymptomatic infections reported in previous

100 studies,[13,15,33,34] we assumed that this period should be less than 30 days, after which virus

101 shedding generally ceases, and infection is no longer detectable through pathogen-specific

102 testing.

103

104 To identify age-varying transmissibility and susceptibility,[22] we assumed a time-varying curve

105 for the average contact numbers of $i^{t h}$ age group with $j^{\text {th }}$ age group $\left(c_{t}^{i j}\right)$, which is estimated

106 with the contact matrix between age groups through surveys conducted in Shanghai.[35,36] We

107 separate the probability of infection into two components: transmissibility $(T)$ and

108 susceptibility (s). We define transmissibility $(T)$ as the infectiousness of one case. Similarly,

109 we define susceptibility $(s)$ as the probability of acquiring infection from an infectious case

$110(T=1)$. Therefore, $s=0$ corresponds to a situation in which the susceptible individuals are

111 immune to the disease. We assumed that case transmissibility would depend on age and the

112 presence of symptoms. To capture the age-dependent pattern, B splines basis functions were 
113 used to model the variability in age-varying transmissibility smoothly. Finally, the

114 compartmental model was fitted to the daily new symptomatic and asymptomatic cases in

115 Zhejiang province for each age group with Markov Chain Monte Carlo (MCMC) algorithm.

116

117 All analyses were implemented in R version 3.5.1. Packages of deSolve,[37] extraDistr,[38] and

118 splines[39] were used for model fitting. Unless stated otherwise, the medians of the posterior

119 distributions were used as the point estimators of parameters and simulated numbers.

\section{Ethics approval}

122 The research protocol was approved by the institutional review board at the Zhejiang Provincial

123 Center for Disease Control and Prevention. The study was based on deidentified data. 


\section{Results}

\section{$\underline{\text { Transmissibility }}$}

128 The estimated transmissibility presented an age-dependent difference between symptomatic and

129 asymptomatic infections (Figure 2). While the transmission of symptomatic cases monotonically 130 increased with increasing age, the transmissibility of asymptomatic infection remained low until 131 age 40, after which point it significantly increased with increasing age. The age-varying ratios of

132 the two kinds of transmissibility indicated asymptomatic cases were, on average, $66.72 \%$ lower

133 in transmission than symptomatic cases. However, the difference between the two types of

134 infections was not as big in those aged 0-20 and 60+ years old, but became more obvious in the

135 middle-aged group where the ratios were as low as $24.42 \%$ and $23.38 \%$ for those aged $30-40$ and 136 40-50 years old, respectively.

The proportion of asymptomatic cases

139 In Figure 3, the proportion of asymptomatic cases $\left(\frac{R_{h}^{i}+R_{c a}^{i}}{R_{h}^{i}+R_{C S}^{i}+R_{c a}^{i}}\right)$ estimated by our model was much 140 larger than what was observed in the data. The average proportion of asymptomatic cases was $14128.22 \%$ (95\%CI: $22.97 \%-34.56 \%$ ) of the total counts of cases in our model estimation, but was

$1429.24 \%$ in the observed data $\left(\frac{R_{c a}^{i}}{R_{c S}^{i}+R_{c a}^{i}}\right)$. In our estimation from the empirical data, the highest 143 proportion of asymptomatic case was among 0-10 (60.18\% (95\%CI: 53.61\% - 66.99\%)) and 144 10-20 (57.64\% (95\%CI: 47.45\% - 66.98\%)) years old groups. For asymptomatic cases, we

145 further estimated the proportion of cases that failed to be detected $\left(\frac{R_{h}^{i}}{R_{h}^{i}+R_{c a}^{i}}\right)$. In the posterior 146 samples, the average proportion of unconfirmed cases in all asymptomatic infections was $14774.10 \%$ (95\%CI: $65.85 \%-80.72 \%$ ). The maximum proportion of unconfirmed cases was 148 observed in 20-30 years old at $86.59 \%$ (95\%CI: $73.64 \%-92.19 \%$ ).

\section{$150 \quad$ Symptomatic and asymptomatic transmission}

151 To explore the impact of symptomatic and asymptomatic transmission, we present several 152 features of the estimated dynamic of the epidemic and the transmission burden caused by 153 symptomatic and asymptomatic cases in Figure 4. The estimated number of daily new 
154 transmissions reached a peak around ten days prior to the peak of the daily reported new

155 confirmed cases (Figure 4A). We estimated a substantial number of undetected asymptomatic

156 cases (109 (95\%CI: 73 - 164)) were infected before the first asymptomatic case was diagnosed

157 (January 27th) (Figure 4B). New transmissions were nearly eliminated by February 2nd, 2020

158 (Figure 4A), when a comprehensive set of restrictions had been implemented. The peak of the

159 two types of transmission both occurred between January 18th to 22nd (Figure 4C). The average

160 burden of asymptomatic transmission during the major outbreak period was estimated to be

161 12.86\% (95\%CI: 7.54\% - 19.27\%). The burden of asymptomatic transmission increased with

162 time, ranging from $7.77 \%$ to $16.03 \%$ (Figure 4D). Simulation studies were conducted to

163 investigate the dynamic changes in the transmission burden over time during a prolonged

164 epidemic. When the duration of the decreasing process of the contact function (represented by

165 " $m$ ") was prolonged by two weeks and each individual's daily contact number was increased by

166 one person during the outbreak period, we found a slower decreasing trend in daily new cases

167 infected by asymptomatic cases compared with that contributed by symptomatic cases.

168 Additional scenarios were generated demonstrating the possibility of asymptomatic transmission

169 dominating the total transmission under different conditions, especially when the duration

170 between symptom onset and disease confirmation for symptomatic infections was shortened and

171 the asymptomatic infections were not controlled.

172

\section{$173 \quad$ Age-depended transmission}

174 Within each age group, we observed heterogeneous transmission contributions during different

175 time periods (Figure 5A). Early on in the epidemic, the transmission burden was dominated by

176 persons of 50-60 years old (32.75\% from January 8th to January 12th), but the proportion of

177 transmission contribution from people over 60 years old significantly increased over time,

178 surpassing the 50-60 years old and reaching 30.42\% by February 1st, 2020. The proportion of

179 transmission contribution among varying age groups was distinct between symptomatic and

180 asymptomatic cases (Figure 5B). The majority of both symptomatic and asymptomatic

181 transmissions were contributed by persons over 30 years old (Table S9). Individuals below 30

182 years old only contributed less than $5 \%$ of all symptomatic transmission and approximately $12 \%$

183 of all asymptomatic transmission, respectively, despite representing almost $40 \%$ of the entire

184 population. Contributions to asymptomatic transmission among 20-30 and >60 year age groups 
185 (9.44\%, and $31.73 \%$, respectively) were substantially higher than their corresponding

186 contributions to symptomatic transmission (3.77\%, and $26.55 \%$, respectively). To further

187 understand possible age-dependent vaccination strategies, a simulation of seven scenarios was

188 conducted to assess the percentage decline in different age groups if one age group were to

189 achieve $100 \%$ immunity by vaccinations. The results suggested that vaccinations targeting age

190 groups above 30 years are likely to be more effective at the population level, with the most

191 percentage decline of cases from the entire population achieved by targeting the 50-60 years old

192 group. Meanwhile, vaccinating those younger than 30 years old are more likely to benefit their 193 own age groups. 


\section{Discussion}

195

196 In our study, we found that asymptomatic cases were over $60 \%$ less infectious compared to

197 symptomatic cases. While great efforts like mass screening and strict contact tracing were

198 conducted, our results suggested that a large proportion of asymptomatic infections were still not 199 detected.[40] The burden of asymptomatic transmission was inferior in the early outbreak but

200 could become higher with the continuous spread of COVID-19. Under strained resources,

201 age-specific prevention and control strategies aimed at the middle age population may return 202 greater population-level benefits.

204 Current evidence suggests that asymptomatic COVID-19 cases are generally less infectious[14] 205 than cases with symptoms. We found that this difference may partially be explained by patient 206 age. Age may directly impact COVID-19 transmission through virus shedding patterns[15] as 207 discussed in previous studies.[41] Symptoms are commonly mild in children[42] but severe in 208 the elderly.[43] While still debatable,[44] higher severity has been associated with increased 209 shedding of the virus.[45] In our study, symptomatic and asymptomatic cases were most 210 infectious in individuals 60 years old or older. In contrary to the monotonic increasing 211 association between age and transmission in symptomatic cases, there was a plateau of a low

212 degree of transmission in young asymptomatic infections. We suspect older adults are not only 213 the most vulnerable to succumb to COVID-19 but also may be more likely to transmit once 214 infected, regardless of symptom status. Interventions attempting to suppress asymptomatic 215 transmission, such as mask-wearing, should primarily focus on older adults if interventions to the 216 whole community are not feasible.

218 Similar to previous studies, our results suggest a small proportion of asymptomatic cases have 219 been detected since the start of the COVID-19 pandemic in our setting.[46-48] Symptom-based 220 screening has limited capability in asymptomatic case detection,[6] while mass pathogen or 221 immunological-based testing at the population-level consumes tremendous health resources, and 222 thus is not feasible in most settings. Considering these challenges, age-dependent screening 223 strategies may be more practical. We found that the highest number of undetected asymptomatic 224 cases was among young adults aged 20 to 30 years old (Table S7) and the corresponding 
225 transmission contribution was significantly higher than that of symptomatic case (Figure 5B).

226 Young people were less likely to adhere to social distancing guidelines,[49] often had mild

227 symptoms or were asymptomatic after infection,[50] and were not prioritized in prevention and

228 controlling strategies.[51] Meanwhile, younger asymptomatic patients were also more likely to

229 have normal CAT scan findings, which may further complicate case detection.[12] Case

230 detection of asymptomatic COVID-19 cases based on current control strategies implemented in

231 this study is alarming.

233 Based on the estimated transmission contributions from symptomatic and asymptomatic

234 infections, roughly $13 \%$ of infections were associated with asymptomatic transmission and that

235 percentage continuously increased with a prolonged period. The overall burden of transmission

236 was mainly contributed by symptomatic cases at the beginning of the epidemic, but

237 asymptomatic infections appeared to have increasing percentages of subsequent cases later on.

238 Additional simulations suggested that the transmission burden could even be dominated by

239 asymptomatic transmissions under certain circumstances. Therefore, the spreading potential of

240 asymptomatic cases cannot be ignored, especially in the later stages of the epidemic and in

241 regions where social distancing has not been mandated. Meanwhile, potential differences in

242 transmission burden by age groups, as shown in Figure 5 and S6, supports prioritizing

243 age-dependent prevention and control strategies when facing strained resources. As the larger

244 contributor to the transmission of COVID-19, the older age population is not only a highly

245 vulnerable group but should also be the primary target for prevention strategies. Vaccine

246 Strategies prioritizing the population between 30-60 years old are likely to have the most

247 population-level benefits.

249 There are several limitations in this study. First, data collection likely missed potential cases of

250 the epidemic, despite intensified efforts devoted by the local investigation team to trace contacts.

251 Due to this, we introduced a compartment in our model $\left(R_{h}^{i}\right)$ to adjust for poor case

252 ascertainment and missing cases. Second, transmissibility and susceptibility were two factors

253 related to symptomatic and asymptomatic transmission estimation and can be difficult to capture

254 simultaneously. We used the susceptibility estimates from a previous study[22] as priors in our

255 model to account for this parameter identification problem. Third, the contact survey data we 
medRxiv preprint doi: https://doi.org/10.1101/2021.05.11.21257060; this version posted September 21, 2021. The copyright holder for this preprint (which was not certified by peer review) is the author/funder, who has granted medRxiv a license to display the preprint in perpetuity.

It is made available under a CC-BY-NC-ND 4.0 International license.

256 used in our model were obtained in Shanghai, a city adjacent to Zhejiang province. Although the

257 two regions share a similar culture and modes of social activities, there were potential

258 uncertainties associated with the discrepancies in contact matrices. To address this limitation, we

259 introduced a correction parameter in our model, so these uncertainties were partially adjusted for

260 in the analyses.

\section{Conclusion}

264 In summary, our results suggest individual-level transmissibility of COVID-19 increases with

265 patient age, therefore targeting older age groups with prevention and intervention strategies is

266 expected to be more efficient. While asymptomatic cases are difficult to trace, the burden of

267 asymptomatic transmission is still sizable and should not be ignored. The results from our study

268 can be used to inform policy decisions on pandemic control and safe reopening. 


\section{References}

270 1. Guan W-J, Ni Z-Y, Hu Y, Liang W-H, Ou C-Q, He J-X, et al. Clinical Characteristics of

271 Coronavirus Disease 2019 in China. N Engl J Med. Massachusetts Medical Society;

272 2020;382:1708-20.

273 2. World Health Organization. WHO Coronavirus Disease (COVID-19) Dashboard (12/12/2020)

274 [Internet]. [cited 2020 Dec 12]. Available from: https://covid19.who.int

275 3. Ferguson N, Laydon D, Nedjati Gilani G, Imai N, Ainslie K, Baguelin M, et al. Report 9:

276 Impact of non-pharmaceutical interventions (NPIs) to reduce COVID19 mortality and healthcare demand [Internet]. Imperial College London; 2020 Mar. Available from:

278 http://spiral.imperial.ac.uk/handle/10044/1/77482

279 4. Prem K, Liu Y, Russell TW, Kucharski AJ, Eggo RM, Davies N, et al. The effect of control 280 strategies to reduce social mixing on outcomes of the COVID-19 epidemic in Wuhan, China: a 281 modelling study. The Lancet Public Health. Elsevier; 2020;5:e261-70.

282 5. Lewnard JA, Lo NC. Scientific and ethical basis for social-distancing interventions against

283 COVID-19. The Lancet Infectious Diseases. 2020;20:631-3.

284 6. Gandhi M, Yokoe DS, Havlir DV. Asymptomatic Transmission, the Achilles' Heel of Current 285 Strategies to Control Covid-19. N Engl J Med. 2020;382:2158-60.

286 7. Huff HV, Singh A. Asymptomatic Transmission During the Coronavirus Disease 2019

287 Pandemic and Implications for Public Health Strategies. Clinical Infectious Diseases.

$288 \quad 2020 ; 71: 2752-6$.

289 8. Rothe C, Schunk M, Sothmann P, Bretzel G, Froeschl G, Wallrauch C, et al. Transmission of

290 2019-nCoV Infection from an Asymptomatic Contact in Germany. N Engl J Med. Massachusetts 291 Medical Society; 2020;382:970-1.

292 9. Holshue ML, DeBolt C, Lindquist S, Lofy KH, Wiesman J, Bruce H, et al. First Case of 2019 293 Novel Coronavirus in the United States. N Engl J Med. 2020;382:929-36.

294 10. Hoehl S, Rabenau H, Berger A, Kortenbusch M, Cinatl J, Bojkova D, et al. Evidence of 295 SARS-CoV-2 Infection in Returning Travelers from Wuhan, China. N Engl J Med.

296 2020;382:1278-80.

297 11. Wölfel R, Corman VM, Guggemos W, Seilmaier M, Zange S, Müller MA, et al. Virological 298 assessment of hospitalized patients with COVID-2019. Nature. 2020;581:465-9.

299 12. Kronbichler A, Kresse D, Yoon S, Lee KH, Effenberger M, Shin JI. Asymptomatic patients 300 as a source of COVID-19 infections: A systematic review and meta-analysis. International 301 Journal of Infectious Diseases. 2020;98:180-6.

302 13. Han MS, Seong M-W, Kim N, Shin S, Cho SI, Park H, et al. Viral RNA Load in Mildly 303 Symptomatic and Asymptomatic Children with COVID-19, Seoul, South Korea. Emerging 304 Infectious Diseases. 2020;26:2497-9. 

asymptomatic SARS-CoV-2 carriers. Respir Med. 2020;169:106026.

307 15. Kim SE, Jeong HS, Yu Y, Shin SU, Kim S, Oh TH, et al. Viral kinetics of SARS-CoV-2 in

308 asymptomatic carriers and presymptomatic patients. Int J Infect Dis. 2020;95:441-3. implications of silent transmission for the control of COVID-19 outbreaks. PNAS. National Academy of Sciences; 2020;117:17513-5.

312 17. Li R, Pei S, Chen B, Song Y, Zhang T, Yang W, et al. Substantial undocumented infection 313 facilitates the rapid dissemination of novel coronavirus (SARS-CoV-2). Science.

314 2020;368:489-93.

315 18. Ferretti L, Wymant C, Kendall M, Zhao L, Nurtay A, Abeler-Dörner L, et al. Quantifying 316 SARS-CoV-2 transmission suggests epidemic control with digital contact tracing. Science 317 [Internet]. American Association for the Advancement of Science; 2020 [cited 2020 Dec 318 21];368. Available from: https://science.sciencemag.org/content/368/6491/eabb6936

319 19. Hu Z, Song C, Xu C, Jin G, Chen Y, Xu X, et al. Clinical characteristics of 24 asymptomatic 320 infections with COVID-19 screened among close contacts in Nanjing, China. Sci China Life Sci. 321 Nature Publishing Group; 2020;63:706-11.

322 20. Huang L, Zhang X, Zhang X, Wei Z, Zhang L, Xu J, et al. Rapid asymptomatic transmission 323 of COVID-19 during the incubation period demonstrating strong infectivity in a cluster of 324 youngsters aged 16-23 years outside Wuhan and characteristics of young patients with 325 COVID-19: A prospective contact-tracing study. J Infect. 2020;80:e1-13.

326 21. Meng H, Xiong R, He R, Lin W, Hao B, Zhang L, et al. CT imaging and clinical course of asymptomatic cases with COVID-19 pneumonia at admission in Wuhan, China. J Infect.

328 2020;81:e33-9.

329 22. Davies NG, Klepac P, Liu Y, Prem K, Jit M, CMMID COVID-19 working group, et al. 330 Age-dependent effects in the transmission and control of COVID-19 epidemics. Nat Med. Nature 331 Publishing Group; 2020;26:1205-11.

332 23. Zhou R, Li F, Chen F, Liu H, Zheng J, Lei C, et al. Viral dynamics in asymptomatic patients 333 with COVID-19. International Journal of Infectious Diseases. 2020;96:288-90.

334 24. Berlin DA, Gulick RM, Martinez FJ. Severe Covid-19. N Engl J Med. Massachusetts 335 Medical Society; 2020;

336 25. Verity R, Okell LC, Dorigatti I, Winskill P, Whittaker C, Imai N, et al. Estimates of the 337 severity of coronavirus disease 2019: a model-based analysis. Lancet Infect Dis.

338 2020;20:669-77. 
26. CDC COVID-19 Response Team. Severe Outcomes Among Patients with Coronavirus Disease 2019 (COVID-19) - United States, February 12-March 16, 2020. MMWR Morb Mortal

341 Wkly Rep. 2020;69:343-6.

27. Kong D, Zheng Y, Wu H, Pan H, Wagner AL, Zheng Y, et al. Pre-symptomatic transmission of novel coronavirus in community settings. Influenza Other Respir Viruses. 2020;14:610-4.

28. Furukawa NW, Brooks JT, Sobel J. Evidence Supporting Transmission of Severe Acute Respiratory Syndrome Coronavirus 2 While Presymptomatic or Asymptomatic. Emerg Infect Dis [Internet]. 2020 [cited 2020 Aug 8];26. Available from: https://www.ncbi.nlm.nih.gov/pmc/articles/PMC7323549/

29. Mizumoto K, Kagaya K, Zarebski A, Chowell G. Estimating the asymptomatic proportion of coronavirus disease 2019 (COVID-19) cases on board the Diamond Princess cruise ship, Yokohama, Japan, 2020. Eurosurveillance [Internet]. 2020 [cited 2020 Apr 5];25. Available

351 from: https://www.eurosurveillance.org/content/10.2807/1560-7917.ES.2020.25.10.2000180

352 30. Bai Y, Yao L, Wei T, Tian F, Jin D-Y, Chen L, et al. Presumed Asymptomatic Carrier

353 Transmission of COVID-19. JAMA. American Medical Association; 2020;323:1406-7.

31. Bureau of Statistics. Zhejiang Provincial Bureau of Statistics: Sixth Census Data [Internet]. 2014 [cited 2020 Jul 30]. Available from:

356 http://tjj.zj.gov.cn/art/2014/9/3/art_1530851_20980968.html

357 32. Chong KC, Cheng W, Zhao S, Ling F, Mohammad KN, Wang MH, et al. Monitoring disease 358 transmissibility of 2019 novel coronavirus disease in Zhejiang, China. International Journal of 359 Infectious Diseases. 2020;96:128-30.

360 33. Long Q-X, Tang X-J, Shi Q-L, Li Q, Deng H-J, Yuan J, et al. Clinical and immunological 361 assessment of asymptomatic SARS-CoV-2 infections. Nat Med. Nature Publishing Group; 362 2020;26:1200-4.

363 34. Lee S, Kim T, Lee E, Lee C, Kim H, Rhee H, et al. Clinical Course and Molecular Viral 364 Shedding Among Asymptomatic and Symptomatic Patients With SARS-CoV-2 Infection in a 365 Community Treatment Center in the Republic of Korea. JAMA Internal Medicine.

$3662020 ; 180: 1447-52$.

367 35. Zhang J, Litvinova M, Liang Y, Wang Y, Wang W, Zhao S, et al. Changes in contact 368 patterns shape the dynamics of the COVID-19 outbreak in China. Science. 2020;368:1481-6.

369 36. Zhang J, Klepac P, Read JM, Rosello A, Wang X, Lai S, et al. Patterns of human social 370 contact and contact with animals in Shanghai, China. Scientific Reports. Nature Publishing 371 Group; 2019;9:15141.

372 37. Soetaert K, Petzoldt T, Setzer RW. Solving Differential Equations in R: Package deSolve. 373 Journal of Statistical Software. 2010;33:1-25.

374 38. Wolodzko T, Wolodzko MT. Package 'extraDistr.' 2017; 
It is made available under a CC-BY-NC-ND 4.0 International license .

39. Perperoglou A, Sauerbrei W, Abrahamowicz M, Schmid M. A review of spline function procedures in R. BMC Medical Research Methodology. 2019;19:46.

40. Flaxman S, Mishra S, Gandy A, Unwin HJT, Mellan TA, Coupland H, et al. Estimating the effects of non-pharmaceutical interventions on COVID-19 in Europe. Nature. Nature Publishing Group; 2020;584:257-61.

41. Esposito S, Principi N. To mask or not to mask children to overcome COVID-19. Eur J Pediatr. 2020;179:1267-70.

42. Dong Y, Mo X, Hu Y, Qi X, Jiang F, Jiang Z, et al. Epidemiology of COVID-19 Among Children in China. Pediatrics. American Academy of Pediatrics; 2020;145:e20200702.

43. Zhou F, Yu T, Du R, Fan G, Liu Y, Liu Z, et al. Clinical course and risk factors for mortality of adult inpatients with COVID-19 in Wuhan, China: a retrospective cohort study. The Lancet. 2020;395:1054-62.

44. He X, Lau EHY, Wu P, Deng X, Wang J, Hao X, et al. Temporal dynamics in viral shedding and transmissibility of COVID-19. Nature Medicine. Nature Publishing Group; 2020;26:672-5.

45. Liu Y, Yan L-M, Wan L, Xiang T-X, Le A, Liu J-M, et al. Viral dynamics in mild and severe cases of COVID-19. The Lancet Infectious Diseases. 2020;20:656-7.

46. Fauci AS, Lane HC, Redfield RR. Covid-19 - Navigating the Uncharted. New England Journal of Medicine. 2020;382:1268-9.

47. García LF. Immune Response, Inflammation, and the Clinical Spectrum of COVID-19. Front Immunol. 2020;11:1441.

48. Oran DP, Topol EJ. Prevalence of Asymptomatic SARS-CoV-2 Infection $\square$ : A Narrative Review. Ann Intern Med. 2020;173:362-7.

49. Czeisler MÉ, Tynan MA, Howard ME, Honeycutt S, Fulmer EB, Kidder DP, et al. Public attitudes, behaviors, and beliefs related to COVID-19, stay-at-home orders, nonessential business closures, and public health guidance-United States, New York City, and Los Angeles, May 5-12, 2020. Morbidity and Mortality Weekly Report. Centers for Disease Control and Prevention; 2020;69:751.

50. Felsenstein S, Hedrich CM. COVID-19 in children and young people. The Lancet Rheumatology. Elsevier; 2020;2:e514-6.

51. Bedford J, Enria D, Giesecke J, Heymann DL, Ihekweazu C, Kobinger G, et al. COVID-19: Towards controlling of a pandemic. The Lancet. 2020;395:1015-8. 
medRxiv preprint doi: https://doi.org/10.1101/2021.05.11.21257060; this version posted September 21, 2021. The copyright holder for this preprint (which was not certified by peer review) is the author/funder, who has granted medRxiv a license to display the preprint in perpetuity.

It is made available under a CC-BY-NC-ND 4.0 International license .

\section{$407 \quad$ Figures}

408

409 Figure 1. Compartmental model for SARS-CoV-2 transmission, where "j” represents another 410 age group different from " $i$ " for the compartments.

412 Figure 2. (A) The estimated transmissibility and 95\% credible intervals for each age group; (B)

413 The ratios of asymptomatic transmissibility to symptomatic transmissibility for seven age groups.

415 Figure 3. The proportion of asymptomatic infections and unconfirmed asymptomatic infections 416 until February 22nd, 2020 for seven age groups.

418 Figure 4. The estimated dynamics of the epidemic and the transmission burdens from

419 symptomatic and asymptomatic cases. (A): The estimated numbers of daily new transmissions

420 with 95\% credible intervals and the observed numbers of daily reported new confirmed cases

421 from January 8th to February 22nd, 2020; (B) The observed numbers of daily reported new

422 confirmed symptomatic $\left(R_{c s}\right)$ and asymptomatic cases $\left(R_{c a}\right)$ and the estimated numbers of daily

423 new cases that failed to be detected $\left(R_{h}\right)$ with $95 \%$ credible intervals; $(C):$ The estimated

424 numbers of infected individuals caused by symptomatic and asymptomatic transmission over

425 time, with 95\% credible intervals; (D): Corresponding proportions of symptomatic and

426 asymptomatic transmissions over different time periods.

428 Figure 5. The burden of transmission caused by different ages. (A) The estimated (contribution)

429 ratios of new transmissions from different ages over different time periods; $(B)$ The estimated

430 (contribution) ratios of symptomatic and asymptomatic transmission from different ages. The

431 contribution ratio of each age group is calculated by the proportion of the transmissions caused

432 by the corresponding age group to the number of all transmissions in each transmission type,

433 from January 8th to February 1st, 2020. 
medRxiv preprint doi: https://doi.org/10.1101/2021.05.11.21257060; this version posted September 21, 2021. The copyright holder for this preprint (which was not certified by peer review) is the author/funder, who has granted medRxiv a license to display the preprint in perpetuity.

It is made available under a CC-BY-NC-ND 4.0 International license .

434 Figure 1. Compartmental model for SARS-CoV-2 transmission, where " $j$ " represents another 435 age group different from " $i$ " for the compartments.

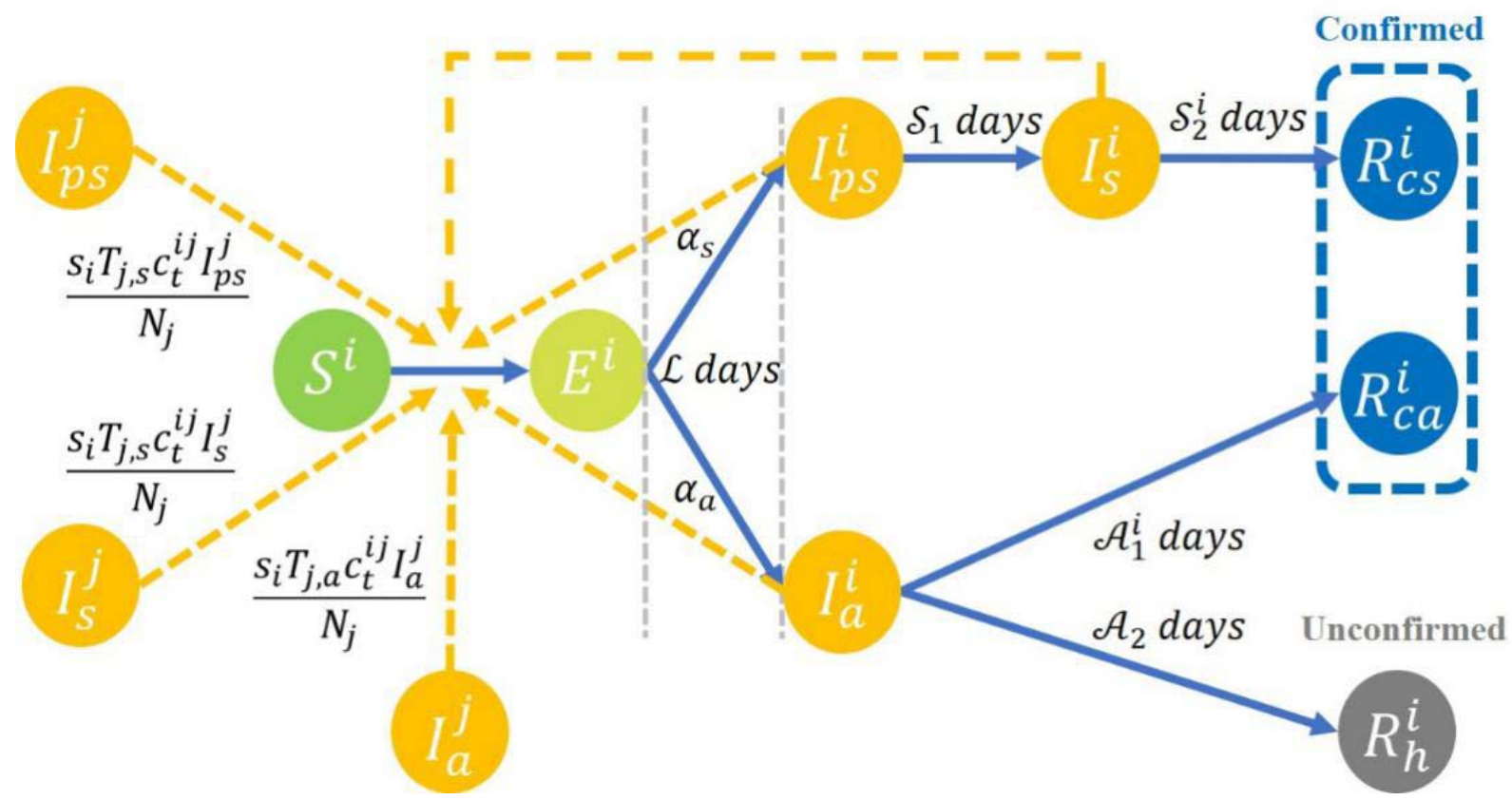


medRxiv preprint doi: https://doi.org/10.1101/2021.05.11.21257060; this version posted September 21, 2021. The copyright holder for this preprint (which was not certified by peer review) is the author/funder, who has granted medRxiv a license to display the preprint in perpetuity.

It is made available under a CC-BY-NC-ND 4.0 International license .

437 Figure 2. (A) The estimated transmissibility and 95\% credible intervals for each age group; (B)

438 The ratios of asymptomatic transmissibility to symptomatic transmissibility for seven age

439 groups.

(A)

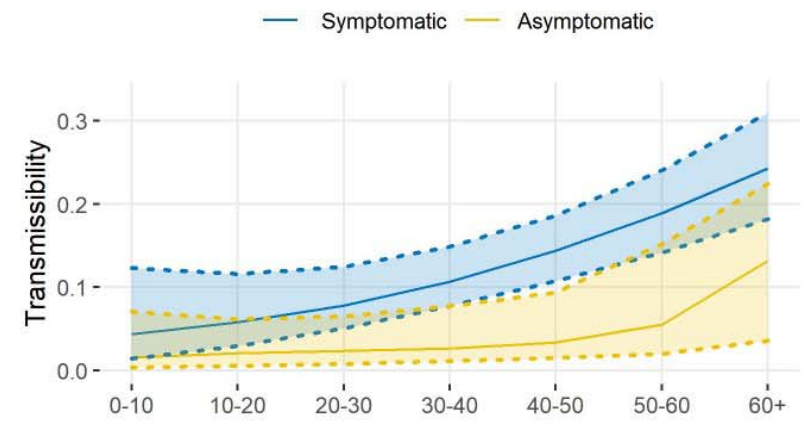


medRxiv preprint doi: https://doi.org/10.1101/2021.05.11.21257060; this version posted September 21, 2021. The copyright holder for this preprint (which was not certified by peer review) is the author/funder, who has granted medRxiv a license to display the preprint in perpetuity.

It is made available under a CC-BY-NC-ND 4.0 International license .

441 Figure 3. The proportion of asymptomatic infections and unconfirmed asymptomatic

442 infections until February 22nd, 2020, for seven age groups. The estimated proportions of

443 asymptomatic cases, the proportions of cases that failed to be detected among asymptomatic

444 infections (unconfirmed proportions), and the observed proportions of asymptomatic cases are

445 defined as: $\frac{R_{h}^{i}+R_{c a}^{i}}{R_{h}^{i}+R_{c s}^{i}+R_{c a}^{i}}, \frac{R_{h}^{i}}{R_{h}^{i}+R_{c a}^{i}}$, and $\frac{R_{c a}^{i}}{R_{c S}^{i}+R_{c a}^{i}}$, respectively. The $95 \%$ credible intervals for the

446 estimated proportions of asymptomatic cases are shown for each age group.

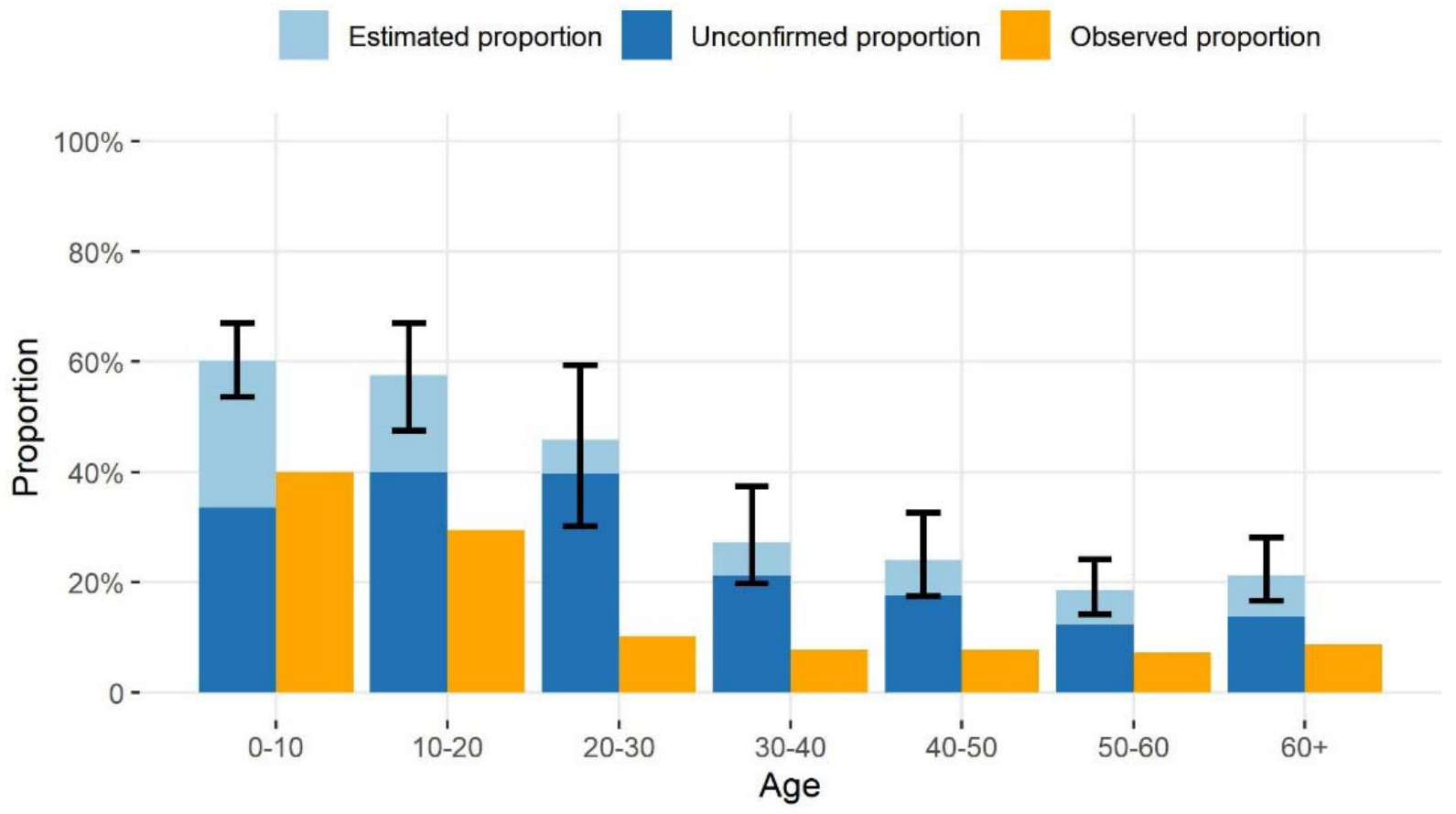


medRxiv preprint doi: https://doi.org/10.1101/2021.05.11.21257060; this version posted September 21, 2021. The copyright holder for this preprint (which was not certified by peer review) is the author/funder, who has granted medRxiv a license to display the preprint in perpetuity.

It is made available under a CC-BY-NC-ND 4.0 International license .

448 Figure 4 . The estimated dynamics of the epidemic and the transmission burdens from

449 symptomatic and asymptomatic cases. (A): The estimated numbers of daily new transmissions

450 with $95 \%$ credible intervals and the observed numbers of daily reported new confirmed cases

451 from January 8th to February 22nd, 2020; (B) The observed numbers of daily reported new

452 confirmed symptomatic $\left(R_{c S}\right)$ and asymptomatic cases $\left(R_{c a}\right)$ and the estimated numbers of daily

453 new cases that failed to be detected $\left(R_{h}\right)$ with $95 \%$ credible intervals; (C): The estimated

454 numbers of infected individuals caused by symptomatic and asymptomatic transmission over

455 time, with 95\% credible intervals; (D): Corresponding proportions of symptomatic and

456 asymptomatic transmissions over different time periods.

(A)

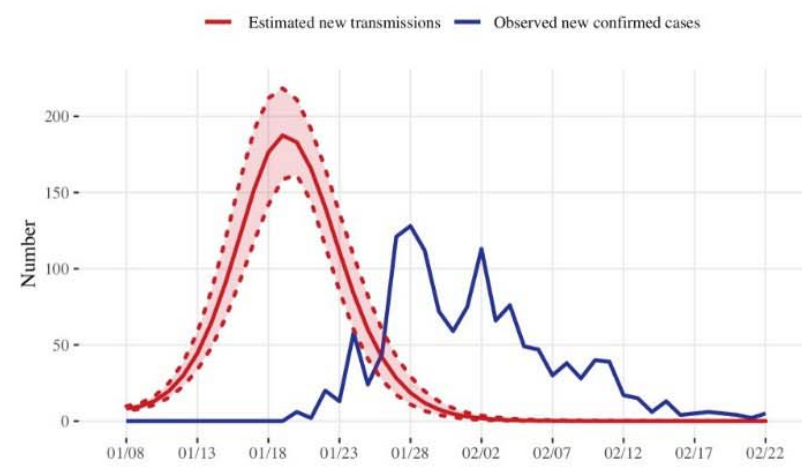

(C)

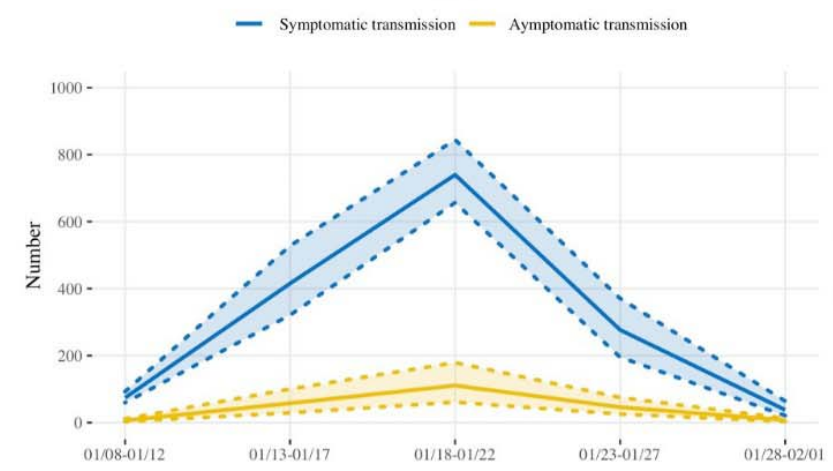

(B)

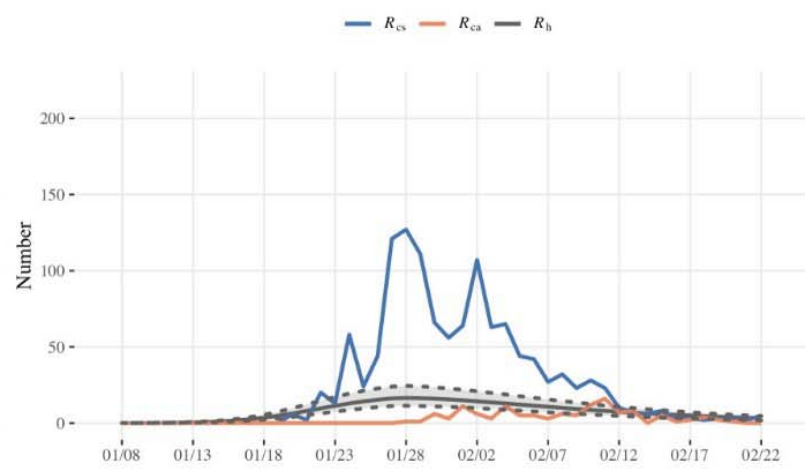

(D)

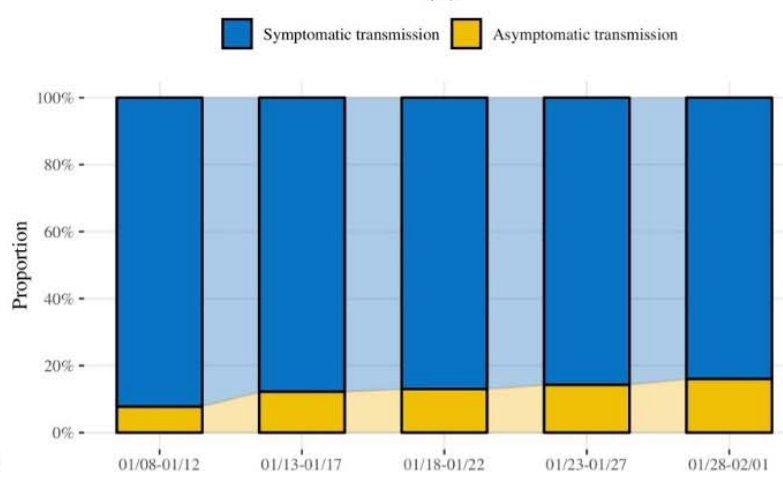


medRxiv preprint doi: https://doi.org/10.1101/2021.05.11.21257060; this version posted September 21, 2021. The copyright holder for this preprint (which was not certified by peer review) is the author/funder, who has granted medRxiv a license to display the preprint in perpetuity.

It is made available under a CC-BY-NC-ND 4.0 International license .

458 Figure 5. The burden of transmission caused by different ages. (A) The estimated (contribution)

459 ratios of new transmissions from different ages over different time periods; (B) The estimated

460 (contribution) ratios of symptomatic and asymptomatic transmission from different ages. The

461 contribution ratio of each age group is calculated by the proportion of the transmissions caused

462 by the corresponding age group to the number of all transmissions in each transmission type,

463 from January 8th to February 1st, 2020.

(A)

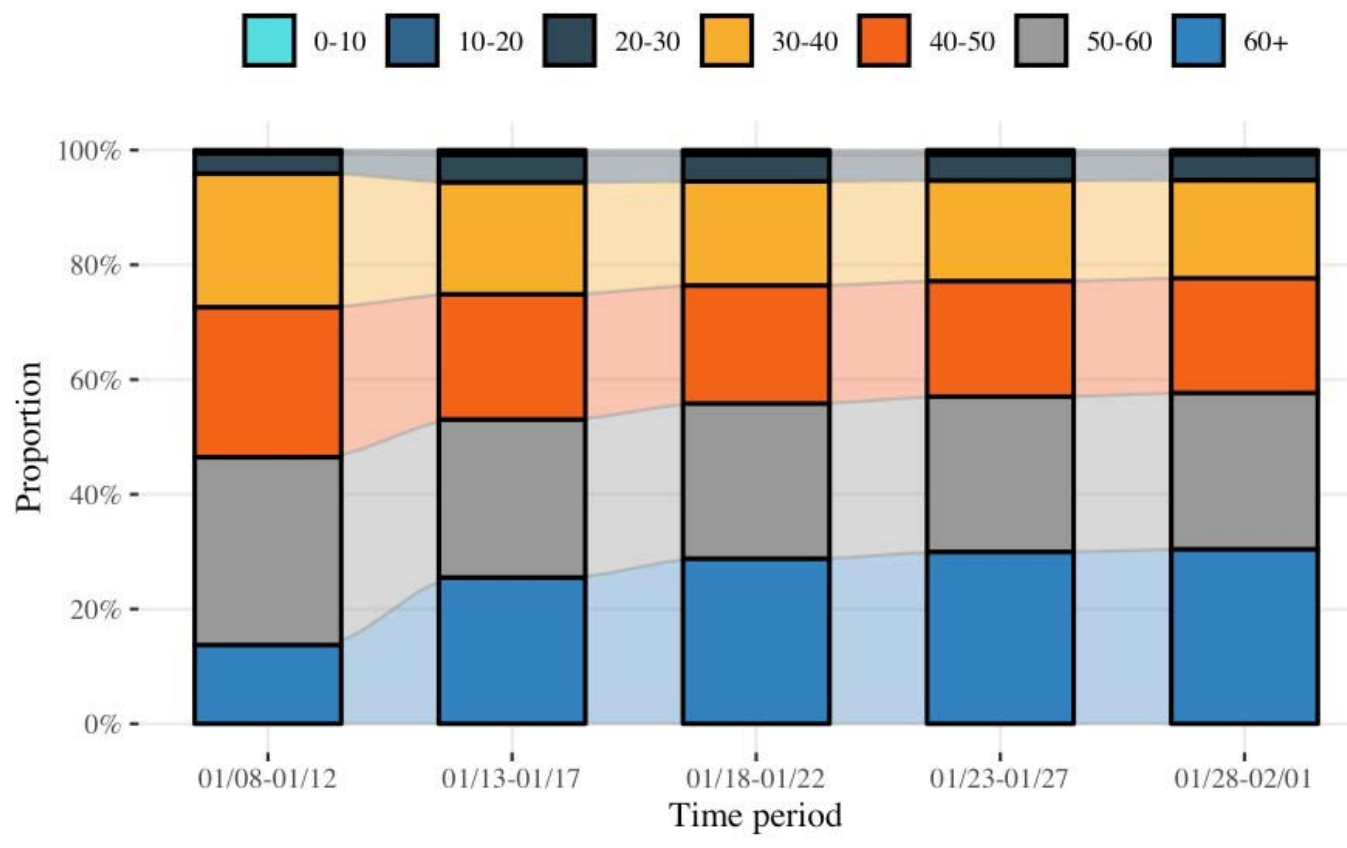

(B)

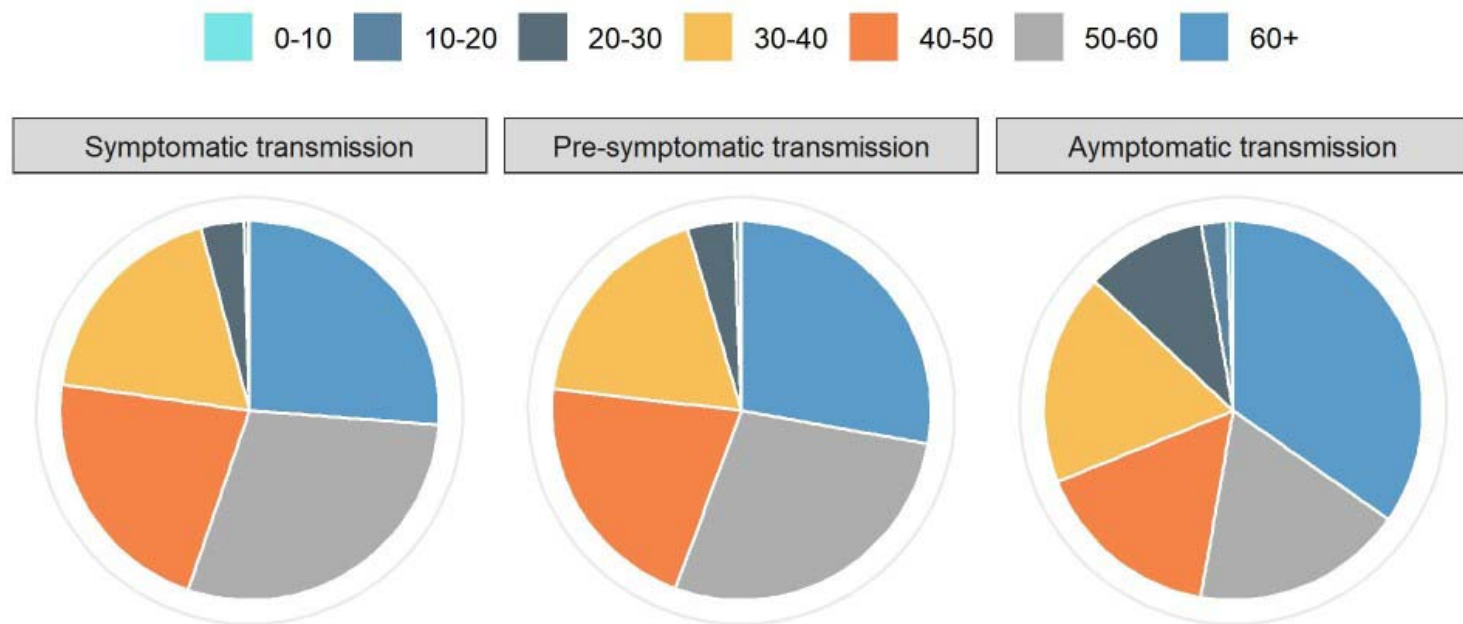

Contribution ratio 